\title{
Adult cancer patients and parents of younger cancer patients have little information about fertility preservation: a survey of knowledge and attitude
}

\author{
Reza Omani-Samani ${ }^{1}$, Samira Vesali ${ }^{2}$ (D), Behnaz Navid ${ }^{2}$, Marzieh Mohajeri ${ }^{3}$, Khadijeh Arjmandi Rafsanjani ${ }^{4}$, \\ Seyyedeh Zahra Nemati Aghamaleki ${ }^{1}$ and Maryam Mohammadi ${ }^{2}$
}

\begin{abstract}
Background: Impaired fertility is one of the side effects of effective cancer therapy. Saving the potential or storing the material to enable people to have biological children after cancer treatment can be of high importance to many cancer survivors. Therefore, we designed a study to determine knowledge and attitudes to fertility preservation (FP) in adult cancer patients and the parents of patients with cancer. Participants who completed this survey were a convenience sample of 384 parents of cancer patients $<18$ years and cancer patients $\geq 18$ years from two large referral hospitals. A 25-item self-administered questionnaire measured knowledge and attitudes to FP. Responses were yes/no, or on a 4-point Likert scale (greatly, usually, rarely, never) scored from 1 for never to 4 for greatly.

Results: Most parents and most cancer patients were unaware of the FP methods of embryo cryopreservation (96.3\% and $88.4 \%$, respectively) and sperm cryopreservation (97.5\% and $89.0 \%$, respectively). Attitudes among cancer patients and parents to use of FP options, based on a 4-point Likert scale, were determined by financial cost, lack of access and information on FP options.

Conclusion: Of concern in this sample of Iranian adult cancer patients and their parents is that knowledge of the fertility risk associated with cancer therapy and knowledge of FP treatment options was generally poor, particularly among the parents. To enable cancer patients or their parents to make the best decisions about using FP services, oncologists and fertility specialists should discuss FP options during their consultation.
\end{abstract}

Keywords: Fertility preservation, Oncofertility, Infertility, Cancer patient, Pediatric

\section{Background}

Nowadays, early detection and advances in medical treatment options, such as chemotherapy, radiation or surgery, have resulted in longer lives with greater reproductive potential for cancer survivors [1,2]. Impaired fertility is one of the side effects of effective cancer therapy [3]. It affects the future quality of life of patients

\footnotetext{
* Correspondence: samiravesali@yahoo.com

${ }^{2}$ Reproductive Epidemiology Research Center, Royan Institute for

Reproductive Biomedicine, ACECR, Tehran, Iran

Full list of author information is available at the end of the article
}

who experience cancer prior to or during their reproductive lifespan [4-6]. Cancer patients who survive and want to have children experience more psychosocial and emotional distress because they are either uncertain about their fertility status or have been confirmed to be infertile $[1,7]$. So, saving the potential or storing the material to enable cancer survivors to have biological children after cancer treatment can be of high importance and help adjustment to life after cancer therapy [8].

There are various fertility preservation (FP) techniques that aim to preserve the childbearing capacity of cancer 
patients or other patients with benign diseases [9]. The FP options currently available for pre- or post-pubertal women and men are ovarian transposition, cryopreservation of embryos, vitrification of oocytes and sperm, and cryopreservation of ovarian and testicular tissue [10].

The Ethics Committee of the American Society for Reproductive Medicine (ASRM) declared in a 2005 statement "Physicians should inform cancer patients about options for FP and future reproduction prior to treatment." [3]. However, after cancer diagnosis, it is important for the physician to minimize any possible delay in the cancer treatment of some patients [5]. Therefore, there is often only a small timeframe for cancer patients to make a cryopreservation decision $[1,11]$. In order to prevent negative experiences and future regret about FP decisions, it is important to make informed decisions regarding FP [12]. The existing literature has shown that cancer patients will be able to make higher-quality decisions if they are aware and fully understand the FP issue. In that sense, cancer patients may have never seriously considered their own beliefs about their reproduction and may need enough time to build self-awareness about this issue [13]. On the other hand, there is disagreement about whether adolescents are competent to make healthcare decisions with long-term consequences. Some evidence on adolescent brain development shows that decision-making and responsibility do not mature until 19 years of age. So, younger adolescents are more likely to make emotional decisions [14-16]. In some countries, like Iran, the legal age of consent is 18 years. Accordingly, parents of patients $<18$ years are responsible for making healthcare decisions for their children. The aim of this study, therefore, was to survey knowledge and attitudes to FP among adult cancer patients and parents of children with cancer, and to determine the extent to which health care providers discuss FP or recommend FP to their patients.

\section{Methods \\ Patients}

In this questionnaire-based study, participants were a convenience sample of cancer patients recently diagnosed (less than 6 months) or under treatment (more than 1 year) by chemotherapy, radiotherapy or surgery from two large referral hospitals in Tehran, Iran. Cancer patients less than 18 years of age were recruited from the Ali-Asghar Hospital, a specialized center for pediatric oncology, and those older than 18 years of age were recruited from the Imam-Khomeini Hospital, a cancer institute for adults. All data were gathered between November 2017 and January 2018.

\section{Study questionnaire}

Based on earlier published data on the issue of FP in adult cancer patients [17] and in parents of pediatric patients with cancer [18], and on the basis of 8 in-depth interviews conducted with a panel of embryologists, gynecologists, and oncologists familiar with FP options in patients with cancer, a 25-item self-administered questionnaire was developed to measure self-reported knowledge and attitudes to FP in parents of cancer patients < 18 years and in cancer patients $\geq 18$ years. Feasibility of the self-completed questionnaire was confirmed by a number of obstetricians and gynecologists, embryologists, and oncologists. In addition, non-physician staff reviewed the questions for clarity. Both the mother and father of cancer patients $<18$ years were asked to fill out the questionnaire together. When this was not possible, the relationship between the person(s) who filled out the questionnaire and the patient $<18$ years was noted. Adult cancer patients $\geq 18$ years responded to the questions themselves. The first part of the questionnaire asked subjects to provide demographic information (sex, age, occupational status, marital status, number of children), duration of suffering from cancer and any infertility history before cancer diagnosis. Parents of cancer patients $<18$ years completed the questions on demographic and clinical characteristics of their children.

The second part of the questionnaire firstly included 7 items (yes/no responses) on the subject's knowledge of FP options, such as cryopreservation of ovarian tissue, oocyte, sperm and testicular tissue, embryo cryopreservation, pre-treatment with Gonadotropin-releasing hormone (GnRH), and ovarian transposition. Secondly, it included three awareness questions (yes/no responses) on the availability of clinics providing FP services in Iran, effects of cancer treatment on fertility, and the possibility of genetic transmission of their cancer to the next generations. Thirdly, the practice behavior of the oncologists treating the cancer patients studied was examined using the question "Have you been referred to reproductive specialists for preserving your fertility (your child's fertility) by your physician?" (yes/no responses). Fourthly, the cancer patients were asked to respond to questions on attitudes towards FP. The questions were as follows: "How important is preserving fertility in cancer patients?"; "How important is use of FP options in cancer patients?"; and "What is the success rate of FP options in cancer patients?" Response options for these three questions were 4-point Likert scales (greatly, usually, rarely, never) scored from 1 for never to 4 for greatly. The next question was on the priority to be given to cancer treatment and starting FP after cancer diagnosis. Participants were allowed to choose an option from therapeutic measures, FP, and no idea. Another question was "If you (your child) become(s) infertile after cancer treatment and you were not aware of possible FP options before starting treatment, who is responsible for the problem?" Participants were asked to 
select one option from cancer patient, patient's family, physician, and fate. The last question asked about characteristics and clinical conditions of the cancer patients that might influence the use of FP. These included the risk of recurrence of the cancer in the future, lack of access to FP services, lack of information on FP options in cancer patients, financial cost, and disappointment with the treatment process and prognosis. Responses were on a 4-point Likert scale (greatly, usually, rarely, never), with scores ranging from 1 for never to 4 for greatly.

\section{Statistical analysis}

Frequencies were summarized for categorical variables. Continuous variables were expressed as mean \pm standard deviation (SD) and 95\% confidence intervals (CIs). $\mathrm{Chi}^{2}$ tests of independence were used to assess relationships between categorical variables derived from answers to yes/no questions. Attitude questions with responses on a 4-point Likert scale were compared using the independent samples $t$ test. The means of these scores indicate the attitude of the population studied. Heeren and D'Agostino, in 1987, demonstrated that this $t$ test is robust for ordinal scaled data [19]. All analyses were carried out using STATA (version 12.0; Stata Corp. LP, College Station, TX). $P$ values of less than 0.05 were considered to indicate statistical significance.

\section{Results}

A total of 397 participants were given a questionnaire, of whom 384 (96.72\%) responded and participated in the study. Among these, 303 participants (78.9\%) were $\geq 18$ years and 81 participants were $<18$ years. The mean age of the respondents was $39.94 \pm 10.38$ years in adult patients $\geq 18$ years and $7.93 \pm 3.94$ in patients $<18$ years. Most cancer patients $<18$ years $(95.1 \%)$ and $\geq 18$ years (78.6\%) were receiving active cancer treatment. The demographic and clinical characteristics of the respondents are presented in Table 1.

\section{Knowledge of FP}

Table 2 lists the knowledge questions on existing FP options used in cancer patients with 7 items covering cryopreservation of ovarian tissue, oocyte, sperm and testicular tissue, embryo cryopreservation, pre-treatment with Gonadotropin-releasing hormone (GnRH), and ovarian transposition (yes/no). Of concern is that the majority of participants were not aware of available FP treatment options, even established FP methods like sperm, oocyte, and embryo cryopreservation. Most parents of cancer patients $<18$ years $(96.3 \%)$ and cancer patients $\geq 18$ years $(88.4 \%)$ did not know about IVF with embryo cryopreservation. There was a statistically significant difference in knowledge between parents of cancer patients $<18$ years and cancer patients $\geq 18$ years $(p$

Table 1 Demographic and clinical characteristics of 384 cancer patients

\begin{tabular}{|c|c|c|c|}
\hline & & $\begin{array}{l}<18 \text { years } \\
N(\%)\end{array}$ & $\begin{array}{l}\geq 18 \text { years } \\
N(\%)\end{array}$ \\
\hline \multirow[t]{2}{*}{ Sex } & Male & $49(60.5)$ & $45(14.9)$ \\
\hline & Female & 32(39.5) & $258(85.1)$ \\
\hline \multirow[t]{5}{*}{ Occupation status } & Housewife & - & 195(68.9) \\
\hline & Employee & - & $34(12)$ \\
\hline & Worker & - & $9(3.2)$ \\
\hline & Student & $47(58)$ & $29(10.2)$ \\
\hline & Self-employed & - & $16(5.7)$ \\
\hline \multirow[t]{2}{*}{ Marital status } & Single & $81(100)$ & $49(16.2)$ \\
\hline & Married & - & $254(83.8)$ \\
\hline \multirow[t]{2}{*}{ Has child/children } & Yes & - & $230(76.2)$ \\
\hline & No & $81(100)$ & $72(23.8)$ \\
\hline \multirow[t]{3}{*}{ Education level } & Under diploma & $80(98.8)$ & $137(46.8)$ \\
\hline & Diploma & - & $98(33.4)$ \\
\hline & academic & - & $58(19.8)$ \\
\hline \multirow[t]{2}{*}{${ }^{a}$ Receiving cancer treatment } & Yes & 77 (95.1) & $232(78.6)$ \\
\hline & No & $4(4.9)$ & $63(21.4)$ \\
\hline \multirow[t]{2}{*}{ Diagnosis of infertility before the start of cancer treatment } & Yes & $1(1.2)$ & $21(7.2)$ \\
\hline & No & $80(98.8)$ & $271(92.8)$ \\
\hline
\end{tabular}

The answer "yes" means cancer patients were being treated (more than 1 year)

aThe answer "no" means cancer patients were recently diagnosed (less than 6 months) 
Table 2 Comparison of participants' knowledge of FP options, awareness of fertility centers providing fertility preservation services, and adverse effects of cancer and cancer treatment by age group $(<18$, respondent $=$ parents; $\geq 18$ respondent $=$ patient $)$

\begin{tabular}{|c|c|c|c|c|}
\hline \multirow{2}{*}{$\begin{array}{l}\text { FP options } \\
\text { Embryo cryopreservation }\end{array}$} & \multicolumn{2}{|c|}{$\begin{array}{l}<18 \text { years } \\
n(\%)\end{array}$} & \multirow{2}{*}{$\begin{array}{l}\geq \mathbf{1 8} \text { years } \\
\boldsymbol{n}(\%) \\
35(11.6)\end{array}$} & \multirow{2}{*}{$\frac{\mathrm{Sig}^{\mathrm{a}}}{0.03^{*}}$} \\
\hline & Yes & $3(3.7)$ & & \\
\hline & No & 78(96.3) & $268(88.4)$ & \\
\hline \multirow[t]{2}{*}{ Ovarian tissue cryopreservation } & Yes & $4(4.9)$ & $30(9.9)$ & 0.19 \\
\hline & No & $77(95.1)$ & $272(90.1)$ & \\
\hline \multirow[t]{2}{*}{ Oocyte cryopreservation } & Yes & $4(4.9)$ & $34(11.3)$ & 0.09 \\
\hline & No & $77(95.1)$ & $268(88.7)$ & \\
\hline \multirow[t]{2}{*}{ Ovarian transposition } & Yes & $3(3.7)$ & $30(10)$ & 0.07 \\
\hline & No & $78(96.3)$ & $271(90)$ & \\
\hline \multirow[t]{2}{*}{ gonadotropin releasing hormones (GnRH) } & Yes & $1(1.2)$ & $17(5.7)$ & 0.13 \\
\hline & No & $80(98.8)$ & $282(94.3)$ & \\
\hline \multirow[t]{2}{*}{ Sperm cryopreservation } & Yes & $2(2.5)$ & $33(11)$ & $0.01^{*}$ \\
\hline & No & $79(97.5)$ & $268(89)$ & \\
\hline \multirow[t]{2}{*}{ Testicular tissue cryopreservation } & Yes & $2(2.5)$ & $22(7.3)$ & 0.12 \\
\hline & No & $79(97.5)$ & $278(92.7)$ & \\
\hline \multicolumn{5}{|l|}{ Awareness } \\
\hline \multirow[t]{2}{*}{ Side effects of cancer treatments on fertility } & Yes & $21(26.3)$ & $41(14.1)$ & $0.01^{*}$ \\
\hline & No & $59(73.8)$ & $250(85.9)$ & \\
\hline \multirow[t]{2}{*}{ The possibility of transferring genes and traits attributed to cancer to the next generation } & Yes & $25(30.9)$ & $116(39.3)$ & 0.16 \\
\hline & No & $56(69.1)$ & $179(60.7)$ & \\
\hline \multirow[t]{2}{*}{ Fertility clinics providing fertility preservation services } & Yes & $8(9.9)$ & $70(23.3)$ & $0.008^{*}$ \\
\hline & No & $73(90.1)$ & $231(76.7)$ & \\
\hline
\end{tabular}

${ }^{*} P<0.05$ was statistically significant

${ }^{a} P$ value is obtained by $\mathrm{chi}^{2}$ test

$=0.03)$. In addition, more than $90 \%$ of parents of cancer patients $<18$ years and almost $89 \%$ of adult cancer patients $\geq 18$ years were not aware of sperm and oocyte cryopreservation. There was a statistically significant difference in knowledge between parents of cancer patients $<18$ years and cancer patients $\geq 18$ years $(p=0.01)$. Table 2 also shows participants' awareness of fertility centers providing FP services, and information on adverse effects of their disease and cancer treatment. Only 21 parents of cancer patients < 18 years $(26.3 \%)$ and 41 cancer patients $\geq 18$ years (14.1\%) were already aware of the fertility risks associated with cancer therapy before the start of cancer treatment. There was a statistically significant difference in knowledge between parents of cancer patients $<18$ years and cancer patients $\geq 18$ years $(p=0.01)$. The majority of parents of cancer patients < 18 years and cancer patients $\geq 18$ years did not know about centers providing FP services. Again, there was a statistically significant difference in knowledge between parents of cancer patients $<18$ years and cancer patients $\geq 18$ years $(p=0.008)$. Fewer than half of the participants were aware of the possibility of transferring genes and traits attributed to cancer to the next generation.

\section{Attitudes toward FP}

A 4-point Likert scale was used for questions on attitudes toward FP with response options $1=$ never; 2 = rarely, 3 = usually, and $4=$ greatly. The median score on this scale is 2.5. Attitudes among cancer patients and parents to use of FP options by cancer patients were determined by financial cost and lack of access and information on FP options. Compared to parents of cancer patients $<18$ years, cancer patients $\geq 18$ years were more influenced by an increased risk of recurrence in the future [2.58 (CI 95\% 1.29-3.87) vs. 2.09 (CI 95\% 0.83-3.35), $p=0.002$ ], and disappointment about the result of treatment and cancer prognosis in relation to using FP options [2.37 (CI 95\% 1.1-3.64) vs. 1.91 (CI 95\% 0.63-3.19), $p=0.005]$ (Table 3). As displayed in Table 3, the importance of preserving fertility, and the success rate and use of FP options by age group hardly differed between the parents of cancer patients $<18$ years and cancer patients $\geq 18$ years. Most respondents felt preserving fertility by using FP options was important, with scores of 3.97 (CI 95\% 3.64-4.3) for parents of cancer patients $<18$ years and 2.32 (CI 95\% 0.93-3.71) for adult 
Table 3 Comparison of participants' attitudes toward factors influencing participants' reasons for enjoying fertility preservation options, importance of preserving fertility, and success rate and use of fertility preservation options by age group

\begin{tabular}{|c|c|c|c|}
\hline Influencing factors & $\begin{array}{l}<18 \text { years } \\
\text { Mean } \pm \text { SD }\end{array}$ & $\begin{array}{l}\geq 18 \text { years } \\
\text { Mean } \pm \text { SD }\end{array}$ & $\mathrm{Sig}^{\mathrm{a}}$ \\
\hline An increased risk of recurrence in the future & $2.09 \pm 1.26$ & $2.58 \pm 1.29$ & $0.002^{*}$ \\
\hline Lack of access to fertility preservation services & $3.44 \pm 1.05$ & $3.00 \pm 1.19$ & $0.003^{*}$ \\
\hline Lack of information on fertility preservation options & $3.75 \pm 0.68$ & $3.17 \pm 1.16$ & $<0.001^{*}$ \\
\hline Cost of fertility preservation options & $3.32 \pm 1.15$ & $3.04 \pm 1.19$ & $0.064^{*}$ \\
\hline Disappointment in the treatment result & $1.91 \pm 1.28$ & $2.37 \pm 1.27$ & $0.005^{*}$ \\
\hline \multicolumn{4}{|l|}{ Importance of FP } \\
\hline Importance of preserving fertility in cancer patients & $3.96 \pm 0.33$ & $2.25 \pm 1.4$ & $<0.0001^{*}$ \\
\hline Importance of using fertility preservation options in cancer patients & $3.97 \pm 0.33$ & $2.32 \pm 1.39$ & $<0.0001^{*}$ \\
\hline The success rate of fertility preservation options in cancer patients & $1.15 \pm 0.62$ & $2.31 \pm 1.18$ & $<0.0001^{*}$ \\
\hline
\end{tabular}

${ }^{*} P<0.05$ was statistically significant

${ }^{a} P$ value is obtained by independent sample test

cancer patients $\geq 18$ years $(p<0.0001)$, and though the low success rate of FP options in cancer patients; scores 1.15 (CI 95\% 0.53-1.77) in parents of cancer patients < 18 years and 2.31 (CI 95\% 1.13-3.49) in cancer patients $\geq 18$ years $(p<0.0001)$. As seen in Fig. 1, 90\% of cancer patients $\geq 18$ years and $72.7 \%$ of parents of cancer patients $<18$ years preferred cancer treatment to starting FP after cancer diagnosis $(p=0.005)$. Only $16 \%$ of adult cancer patients $\geq 18$ years and $18.3 \%$ of parents of cancer patients $<18$ years believed that the physician is responsible for infertility after cancer treatment through not making cancer patients aware of FP options before starting treatment $(p<0.0001)$ (Fig. 2). The vast majority of respondents declared that the oncologists who were treating the cancer patients did not refer them to a reproductive specialist for preserving fertility, although, again, there was an evidence of an age group difference $(p=0.01)$ (Fig. 3).

\section{Discussion}

The most important finding of the present study was that the majority of cancer patients $\geq 18$ years and parents of cancer patients $<18$ years had limited knowledge of FP options and were not aware of the adverse effect on fertility of cancer treatment. This finding is in contrast with what has been reported in some studies. Balthazar et al. provided a quantitative assessment of female patients' knowledge about fertility and FP treatment options before the initial FP consultation, and revealed that the mean knowledge score for 41 women aged 18 to 41 years was $5.9 \pm 2.7$, out of a maximum

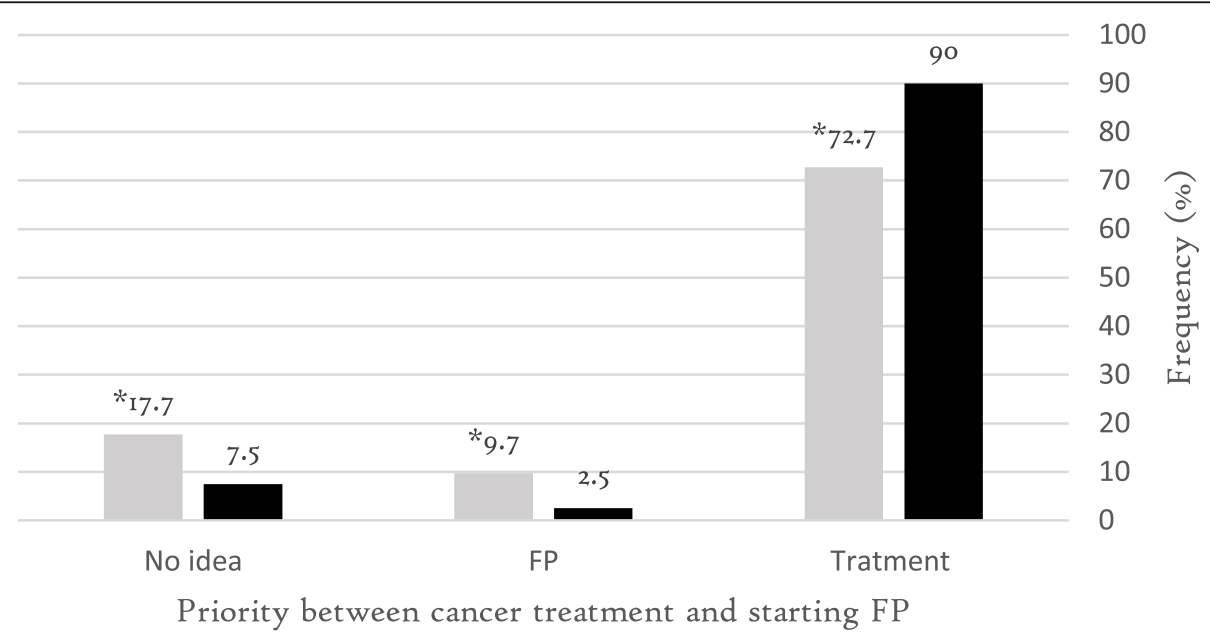

$<18 \quad \geq 18$

Fig. 1 Comparison of participants' attitudes toward priority between cancer treatment and starting FP after cancer diagnosis by age group, $p$ $=0.005$ 


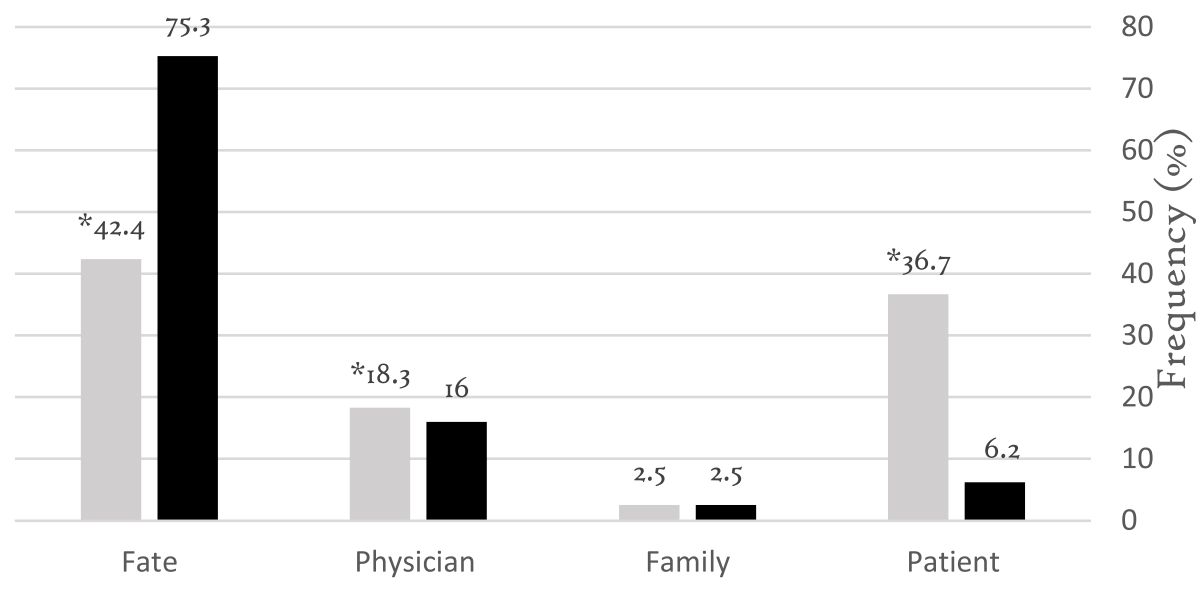

Responsibility for post-cancer treatment infertility

Fig. 2 Comparison of participants' attitude toward responsibility for post-cancer infertility treatment in cancer patients by age group, $p<0.0001$

possible score of 13. Many patients were also aware that different cancer treatments have varying effects on fertility [20]. A cross-sectional online survey conducted by Urech et al. in 155 young female cancer patients from English- and German-speaking countries assessed knowledge about and attitudes towards FP. In this study, approximately two-thirds of participants knew about techniques like freezing embryos or freezing egg cells. Other FP techniques, such as hormonal protection of the ovaries, freezing ovarian tissue, organ-preserving surgery, freezing immature eggs or in vitro maturation of eggs were less known [21]. A survey on attitudes of female adolescent cancer patients (ACPs) aged 15-21 years and their parents toward FP techniques in the case of infertility from cancer treatment showed that a total of $69 \%$ of ACPs were aware of the problem of infertility. However, only $31 \%$ recalled being spoken to about treatment effects on fertility [22]. Shnorhavorian et al., conducted a study of 459 adolescent and young adult (AYA) cancer patients diagnosed between 2007 and 2008 and recruited through seven US population-based cancer registries. The authors found that $80 \%$ of males and $74 \%$ of females knew that cancer therapy might affect fertility. However, $29 \%$ of the males and $56.3 \%$ of females reported not discussing FP prior to starting cancer treatment [17]. A retrospective cohort study included the

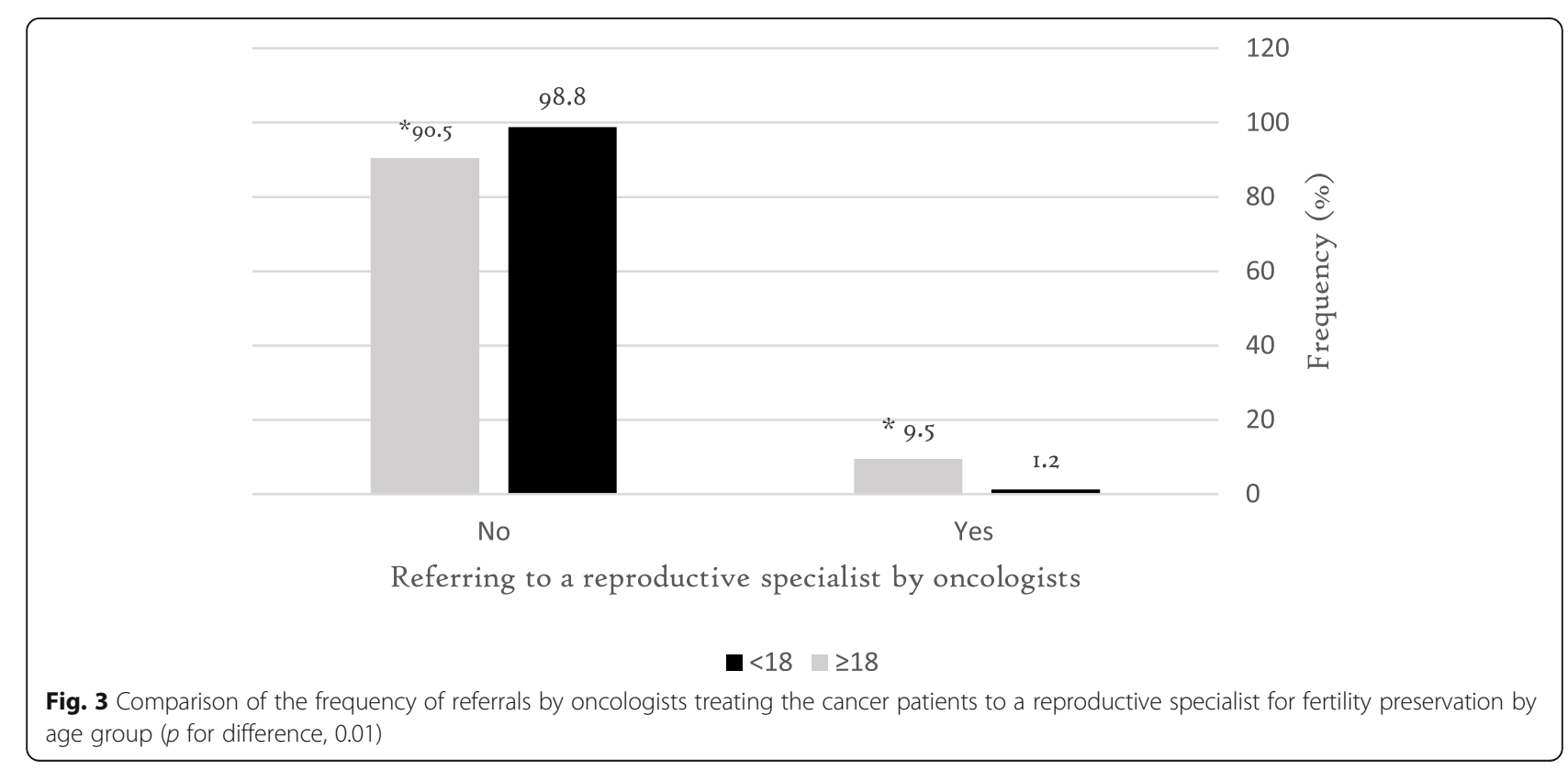


parents of all boys who were diagnosed with cancer from December 1990 to December 2009 at the Mahak Institute in Tehran, Iran, and their children who were still alive. Only $22 \%$ of all parents reported that they knew about the effect of cancer treatment on fertility before they received this questionnaire. Of those parents who were aware of the effects of cancer treatment on fertility before they received the questionnaire, only one-third had been informed about this by the treating physician [18]. Consequently, awareness of fertility impairment or loss related to cancer therapy in those suffering from cancer steadily improve with increasing oncologists' awareness of the importance of FP issues [23]. The American Society for Clinical Oncology (ASCO) outlines how cancer treatment regimens, multi-agent therapy, and cumulative treatment may affect fertility. The authors of these recommendations confirmed that "oncologists should address the possibility of infertility with patients treated during their reproductive years and be prepared to discuss possible FP options or refer appropriate and interested patients to reproductive specialists". Therefore, the potential risk should be discussed with all pubertal or post-pubertal patients at the time of diagnosis. It has been suggested that the discussion should include an explanation of potential methods of FP [24]. Findings of the current survey suggest that the vast majority of respondents declared that the oncologists who were treating the cancer patients did not refer them to a reproductive specialist for preserving fertility. Possible reasons for this may be one of 3 causes, including lack of national guidelines, advanced stage cancer at the time of diagnosis, pre-pubertal diagnosis of cancer.

It is worth noting that the existing gaps in oncologists' knowledge of FP options and their referral behavior are of reasons for not making FP arrangements. In this regard, other barriers to FP reported by US male and female AYAs included being unaware of options, cost issues, the physician or patient not wanting to delay treatment, the effect of cancer on future offspring, and not wanting biological children. Findings from the current survey are in line with some of the reasons mentioned by US AYAs, such as cost and lack of information on and access to FP services [17]. It is notable that the differences are inevitable because the cultural context in which the surveys took place is widely different.

Burns et al. investigated whether female adolescents with a diagnosis of cancer and their parents were interested in trying to preserve fertility. They found that adolescents and parents were interested in preserving fertility, but not willing to postpone cancer therapy [25]. In accordance with this study, most cancer patients $\geq 18$ years and parents of cancer patients $<18$ years in the current survey had strongly positive attitude toward prioritizing their cancer treatment to starting FP after they had been diagnosed with cancer. However, many parents of cancer patients $<18$ agreed with the importance of preserving childbearing capacity and the use of FP options in cancer patients.

Although ASCO and ASRM guidelines highlight that oncologists have a responsibility to inform patients that cancer treatment may affect fertility [6], in the current survey a minority of cancer patients $\geq 18$ years and parents of cancer patients $<18$ years felt that it is the physician who is responsible for infertility after cancer treatment through not providing information on FP options before starting treatment.

\section{Study limitations}

There are several limitations to the current survey. First, there is the possibility of selection bias in our study population, with the findings open to the influence of non-clustered sampling and heterogeneity due to age, type of malignancy, and type and number of chemotherapeutic agents. They may, thus not be representative of the entire population of oncological patients in Iran or further afield. Second, there is the possibility of reporting bias: the questionnaire was not validated quantitatively. The self-reported nature of the survey may also have led to an under estimation of FP behavior of oncologists and so may not be representative of actual practice. However, few objective measures of FP knowledge and attitudes among cancer patients $\geq 18$ years and parents of cancer patients $<18$ years are available from routine data so this is an unavoidable limitation.

\section{Conclusion}

The current survey provides concerning evidence that knowledge at diagnosis about FP treatment options and adverse effects of cancer treatment in a sample of Iranian adult cancer patients $\geq 18$ years and Iranian parents of cancer patients $<18$ years is generally poor. To facilitate the best decisions about use of FP services by cancer patients, oncologists and fertility specialists should introduce information about FP options during their consultation, focusing particularly on parents of patients under the age of 18. The data indicate that uptake of FP among cancer patients and parents is influenced most by financial cost, lack of access to FP options, and information on FP options. Better awareness and understanding of these issues will enhance patients' decision-making about FP options and help improve quality of care. The current study provides good insight into future initiatives to improve FP care.

\section{Abbreviations}

FP: Fertility preservation; ASRM: American Society for Reproductive Medicine; $\mathrm{GnRH}$ : Gonadotropin-releasing hormone; SD: Standard deviation;

Cls: Confidence intervals; ASCO: American Society for Clinical Oncology 


\section{Supplementary Information}

The online version contains supplementary material available at https://doi. org/10.1186/s43043-021-00072-5.

\section{Additional file 1.}

\section{Acknowledgements}

We would like to thank Dr. R. Safaei (head of an oncology and hematology ward in Imam Hospital) for her assistance with all aspects of study design and implementation.

\section{Authors' contributions}

ROS: study design, approved the final version, and agreed to be accountable for the work. BN: data acquisition. MM: statistical analysis. ZNA: data acquisition. KA: study design and data acquisition. SV: data acquisition, drafting of manuscript, and manuscript revision. All authors have read and approved the manuscript.

\section{Funding}

Not applicable

\section{Availability of data and materials}

The datasets used and/or analyzed during the current study are available from the corresponding author on reasonable request.

\section{Declarations}

\section{Ethics approval and consent to participate}

Ethical approval was obtained from the Ethics Committee of the Royan Institute (IR.ACER.ROYAN.REC.1394.158). The aims of the study were clearly explained to all participants prior to the investigation, and confidentiality and anonymity was assured. Voluntary completion of the questionnaire was considered as written consent.

\section{Consent for publication}

Not applicable.

\section{Competing interests}

The authors declare that they have no competing interests.

\section{Author details}

'Department of Medical Ethics and Law, Reproductive Biomedicine Research Center, Royan Institute for Reproductive Biomedicine, ACECR, Tehran, Iran. ${ }^{2}$ Reproductive Epidemiology Research Center, Royan Institute for Reproductive Biomedicine, ACECR, Tehran, Iran. ${ }^{3}$ Department of Clinical Psychology, Faculty of Psychology and Educational Science, Kharazmi University, Tehran, Iran. ${ }^{4}$ Hematology Oncology Research Center, Aliasghar Children Hospital, Iran University of Medical Sciences, Tehran, Iran.

Received: 25 March 2021 Accepted: 5 August 2021

Published online: 14 August 2021

\section{References}

1. Yee S, Abrol K, McDonald M, Tonelli M, Liu KE (2012) Addressing oncofertility needs: views of female cancer patients in fertility preservation. J Psychosoc Oncol 30(3):331-346. https://doi.org/10.1080/07347332.2012.6642 57

2. Maltaris T, Seufert R, Fischl F, Schaffrath M, Pollow K, Koelbl H, Dittrich R (2007) The effect of cancer treatment on female fertility and strategies for preserving fertility. Eur J Obstet Gynecol Reprod Biol 130(2):148-155. https:// doi.org/10.1016/j.ejogrb.2006.08.006

3. Lee SJ, Schover LR, Partridge AH, Patrizio P, Wallace WH, Hagerty K, Beck LN, Brennan LV, Oktay K, American Society of Clinical Oncology (2006) American Society of Clinical Oncology recommendations on fertility preservation in cancer patients. J Clin Oncol 24(18):2917-2931. https://doi.org/10.1200/ JCO.2006.06.5888

4. Quinn GP, Murphy D, Knapp C, Stearsman DK, Bradley-Klug KL, Sawczyn K, Clayman ML (2011) Who decides? Decision making and fertility preservation in teens with cancer: a review of the literature. J Adolesc Health 49(4):337346. https://doi.org/10.1016/j.jadohealth.2011.01.005
5. Lobo RA (2005) Potential options for preservation of fertility in women. N Engl J Med 353(1):64-73. https://doi.org/10.1056/NEJMra043475

6. Loren AW, Mangu PB, Beck LN, Brennan L, Magdalinski AJ, Partridge AH, Quinn G, Wallace WH, Oktay K, American Society of Clinical Oncology (2013) Fertility preservation for patients with cancer: American Society of Clinical Oncology clinical practice guideline update. J Clin Oncol 31(19):2500-2510. https://doi.org/10.1200/JCO.2013.49.2678

7. Patel A et al (2009) Reproductive health assessment for women with cancer: a pilot study. Am J Obstet Gynecol 201(2):191 e1-4

8. Tschudin S, Bitzer J (2009) Psychological aspects of fertility preservation in men and women affected by cancer and other life-threatening diseases. Hum Reprod Update 15(5):587-597. https://doi.org/10.1093/humupd/ dmp015

9. Reis N, Beji NK, Coskun A (2010) Quality of life and sexual functioning in gynecological cancer patients: results from quantitative and qualitative data. Eur J Oncol Nurs 14(2):137-146. https://doi.org/10.1016/ j.ejon.2009.09.004

10. Jeruss JS, Woodruff TK (2009) Preservation of fertility in patients with cancer. N Engl J Med 360(9):902-911. https://doi.org/10.1056/NEJMra0801454

11. Baysal O, Bastings L, Beerendonk CCM, Postma SAE, IntHout J, Verhaak CM, Braat DDM, Nelen WLDM (2015) Decision-making in female fertility preservation is balancing the expected burden of fertility preservation treatment and the wish to conceive. Hum Reprod 30(7):1625-1634. https:// doi.org/10.1093/humrep/dev116

12. Bastings $L$, Baysal $\mathrm{O}$, Beerendonk CCM, IntHout J, Traas MAF, Verhaak CM, Braat DDM, Nelen WLDM (2014) Deciding about fertility preservation after specialist counselling. Human Reproduction 29(8):1721-1729. https://doi. org/10.1093/humrep/deu136

13. Kim J, Mersereau JE (2015) Early referral makes the decision-making about fertility preservation easier: a pilot survey study of young female cancer survivors. Support Care Cancer 23(6):1663-1667. https://doi.org/10.1007/ s00520-014-2526-3

14. Cauffman E, Steinberg L (2000) (Im)maturity of judgment in adolescence: why adolescents may be less culpable than adults. Behav Sci Law 18(6): 741-760. https://doi.org/10.1002/bsl.416

15. Weithorn LA, Campbell SB (1982) The competency of children and adolescents to make informed treatment decisions. Child Dev 53(6):15891598. https://doi.org/10.2307/1130087

16. Broome ME, Richards DJ (2003) The influence of relationships on children's and adolescents' participation in research. Nurs Res 52(3):191-197. https:// doi.org/10.1097/00006199-200305000-00009

17. Shnorhavorian M, Harlan LC, Smith AW, Keegan THM, Lynch CF, Prasad PK, Cress RD, Wu XC, Hamilton AS, Parsons HM, Keel G, Charlesworth SE, Schwartz SM, AYA HOPE Study Collaborative Group (2015) Fertility preservation knowledge, counseling, and actions among adolescent and young adult patients with cancer: A population-based study. Cancer 121(19):3499-3506. https://doi.org/10.1002/cncr.29328

18. Sadri-Ardekani $H$, Akhondi MM, Vossough P, Maleki H, Sedighnejad S, Kamali K, Ghorbani B, van Wely M, van der Veen F, Repping S (2013) Parental attitudes toward fertility preservation in boys with cancer: context of different risk levels of infertility and success rates of fertility restoration. Fertil Steril 99(3):796-802. https://doi.org/10.1016/j.fertnstert.2 012.11 .030

19. Heeren T, D'Agostino R (1987) Robustness of the two independent samples t-test when applied to ordinal scaled data. Stat Med 6(1):79-90. https://doi. org/10.1002/sim.4780060110

20. Balthazar, U., M.A. Fritz, and J.E. Mersereau, Fertility preservation: a pilot study to assess previsit patient knowledge quantitatively. Fertil Steril, 2011. 95(6): 1913-6, DOI: https://doi.org/10.1016/j.fertnstert.2011. 02.016 .

21. Urech C, Ehrbar V, Boivin J, Müller M, Alder J, Zanetti Dällenbach R, Rochlitz C, Tschudin S (2018) Knowledge about and attitude towards fertility preservation in young female cancer patients: a cross-sectional online survey. Hum Fertil (Camb) 21(1):45-51. https://doi.org/10.1080/14647273.201 7.1380317

22. Loi K, Lau M, Loh SF, Tan YY, Hong GS, Chan MY, Tan AM (2010) Attitudes toward fertility preservation in female cancer patients. J Reprod Med 55(910):411-416

23. Adams E, Hill E, Watson E (2013) Fertility preservation in cancer survivors: a national survey of oncologists' current knowledge, practice and attitudes. Br J Cancer 108(8):1602-1615. https://doi.org/10.1038/bjc.2013.139 
24. Yeomanson DJ, Morgan S, Pacey AA (2013) Discussing fertility preservation at the time of cancer diagnosis: dissatisfaction of young females. Pediatr Blood Cancer 60(12):1996-2000. https://doi.org/10.1002/ pbc. 24672

25. Burns KC, Boudreau C, Panepinto JA (2006) Attitudes regarding fertility preservation in female adolescent cancer patients. J Pediatr Hematol Oncol 28(6):350-354. https://doi.org/10.1097/00043426-2 00606000-00006

\section{Publisher's Note}

Springer Nature remains neutral with regard to jurisdictional claims in published maps and institutional affiliations.

Submit your manuscript to a SpringerOpen ${ }^{\circ}$ journal and benefit from:

- Convenient online submission

- Rigorous peer review

- Open access: articles freely available online

- High visibility within the field

- Retaining the copyright to your article

Submit your next manuscript at $\boldsymbol{\nabla}$ springeropen.com 